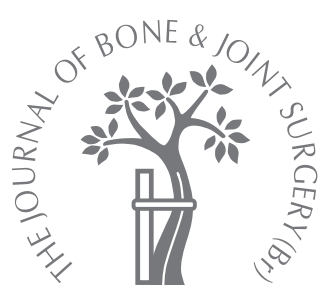

I. Landor,

P. Vavrik,

D. Jahoda,

D. Pokorny,

A. Tawa,

A. Sosna

From Charles

University, Prague,

Czech Republic

\title{
The Long Oblique Revision component in revision arthroplasty of the hip
}

\begin{abstract}
Migration of the acetabular component may give rise to oval-shaped bone defects in the acetabulum. The oblong implant is designed to fill these defects and achieve a stable cementless anchorage with no significant bone loss. We prospectively reviewed 133 oblong long oblique revision components at a mean follow-up of 9.74 years ( 0.6 to 14$)$. All had been used in revisions for defects of type IIB to IIIB according to Paprosky. Aseptic loosening was the reason for revision in 11 cases (8.3\%) and deep infection in seven (5.3\%). The probability of implant survival over a 12-year follow-up estimated by the Kaplan-Meier method gave a survival rate of $0.85 \%$ respectively $0.90 \%$ when deep infection was excluded as the endpoint.

Our study supports the use of these components in defects from IIB to IIIA. The main precondition for success is direct contact of more than half of the surface of the implant with the host acetabular bone.
\end{abstract}

Loosening and migration of acetabular components may give rise to extensive bone defects, leaving an elongated, oval cavity, usually because of proximal or proximolateral migration of the implant. Revision may then be difficult using a conventional device, especially when the length of the defect is greater than the transverse diameter. If an oblong defect is revised with a standard implant, three options are usually available. A jumbo acetabular component may be used, in which case the anteroposterior diameter of the acetabulum has to be widened to accommodate it. ${ }^{1-3}$ This additional bone loss may endanger the stability of the pelvic ring and should be restricted to cases where the difference between the longitudinal and transverse acetabular diameters is no more than $10 \mathrm{~mm} .{ }^{4} \mathrm{~A}$ second approach is to locate the hip high, with a small standard implant fixed in the proximal portion of the residual acetabular vault. ${ }^{5,6}$ Biomechanical problems due to the high positioning of the centre of rotation of the hip may result in loosening of the acetabular or femoral components. ${ }^{7-9}$ Support rings, wire mesh and fixation screws may also be used, but with differing levels of success. ${ }^{10-15}$ The high complication rate following revision surgery emphasises the need for better long-term solutions.

Another approach could be to use an implant which is adapted to the existing defect in size and shape in order to achieve primary stable uncemented anchorage without using extensive bone allografting, and thereby optimise osseous integration without sacrificing residual bone. The implant should be supported on the available residual bone, so that only the remaining defects require filling with bone graft. The long oblong revision acetabular component (Sulzer Orthopedics GmbH, Freiburg, Germany) was designed for this purpose, ${ }^{16,17}$ and we have used it in large acetabular defects.

\section{Materials and Methods}

Between 1993 and 1999, 133 long oblique revision components were implanted in revision procedures in 111 patients with a mean age of 62.2 years ( 31 to 83 ) at the time of the operation. The mean follow-up was for 9.74 years $(0.6$ to 14$)$. No patient was lost to follow-up, but six with six acetabular components died from unrelated diseases during the study period. Their data were taken into consideration in the clinical evaluation. Revision was carried out for the first time in 62 cases, for the second time in 53, for the third time in 17 and for the fourth time in one. The indications for revision and the initial diagnosis for which the primary total hip replacement (THR) was carried out are shown in Table I. In infected hips the revision component was inserted as a second procedure six weeks after removal of the primary implant. The femoral component was exchanged in 32 cases. The 
Table I. Indications for long oblique revision (LOR) component and primary total hip replacement (THR)

\begin{tabular}{lr}
\hline & Number \\
\hline Indication for LOR component & \\
Aseptic loosening & 103 \\
$\quad$ Cemented & 19 \\
$\quad$ Cementless & \\
Septic loosening (two stage replantation) & 10 \\
$\quad$ Cemented & 1 \\
$\quad$ Cementless & 133 \\
Total & \\
& \\
Indication for primary THR & 98 \\
$\quad$ Primary osteoarthritis & 20 \\
$\quad$ Secondary osteoarthritis & 15 \\
Rheumatoid arthritis & 133 \\
Total &
\end{tabular}

Table II. Characteristics of original implants (original implant in two-stage reimplantation included)

\begin{tabular}{lclclc}
\hline Fixation type & Number (\%) & Head size (mm) & Number (\%) & Bearing surfaces & Number (\%) \\
\hline Cemented & $109(82.0)$ & 32 & $129(97.0)$ & $\mathrm{PE}^{*} /$ metal & $86(64.7)$ \\
Cementless & $24(18.0)$ & 28 & $4(3.0)$ & PE/ceramic & $47(35.3)$ \\
Total & $133(100.0)$ & & $133(100.0)$ & & $133(100.0)$ \\
\hline
\end{tabular}

* PE, polyethylene

Table III. Occurrence of acetabular defects classified according to Paprosky and Momberger ${ }^{18}$

\begin{tabular}{lc}
\hline Defect type & Number (\%) \\
\hline IIB & $22(16.5)$ \\
IIC & $18(13.5)$ \\
IIIA & $83(62.4)$ \\
IIIB & $10(7.5)$ \\
Total & $133(100.0)$ \\
\hline
\end{tabular}

original implants are listed in Table II. The acetabular defects were classified according to Paprosky and Momberger $^{18}$ (Table III). All were either type IIB or type IIIB. The high proportion of type III defects accounted for the frequent use of components with ovality of $12 \mathrm{~mm}$ (Table IV).

The acetabular bed was prepared using standard spherical reamers to allow the introduction of the appropriate component with minimal removal of bone. Small cavitary defects were filled with morcellised homologous bone, which was used in 118 cases (89\%). No structural graft was used. The anteroposterior acetabular walls were preserved as far as possible. The titanium shell was inserted as a slightly oversized press-fit and was fixed with no fewer than three additional titanium screws placed in the ilium, pubis and ischium in all cases (Table V). The appropriate polyethylene insert was applied using the snap-fit mechanism. All procedures were performed by the authors through the transgluteal approach. ${ }^{19}$ Patients were given a prophylactic dose of antibiotic 48 hours after operation, except in cases where reimplantation followed extraction of a prosthesis for deep infection, when antibiotics were given for six weeks. Partial weight-bearing was allowed in the sixth week, with full weight-bearing after 12 weeks.

Clinical and radiographic evaluation was undertaken by the authors before and at three, six and 12 months after operation, after which the patients were reviewed annually. A routine physical examination and calculation of the Harris Hip Score ${ }^{20}$ (HHS) were carried out at every assessment. Radiological evaluation included anteroposterior and lateral views taken before and immediately after surgery, at three and six months, and then yearly. Translucencies were assessed according to Johnston et $\mathrm{al}^{21}$ and migration of the component measured according to the method of Nunn et al. ${ }^{22}$ All criteria were evaluated in different zones according to DeLee and Charnley, ${ }^{23}$ with modification for 
Table IV. The sizes of the long oblique revision component which were used

\begin{tabular}{|c|c|c|c|}
\hline \multicolumn{2}{|c|}{ Ovality 6 mm } & \multicolumn{2}{|c|}{ Ovality 12 mm } \\
\hline Size (mm) & Number (\%) & Size $(\mathrm{mm})$ & Number (\%) \\
\hline $52 \times 58$ & $4(3)$ & $52 \times 64$ & $25(19)$ \\
\hline $56 \times 62$ & $7(5)$ & $56 \times 68$ & $32(24)$ \\
\hline $60 \times 66$ & $6(5)$ & $60 \times 72$ & $22(17)$ \\
\hline $64 \times 70$ & $11(8)$ & $64 \times 76$ & $11(8)$ \\
\hline $68 \times 74$ & $7(5)$ & $68 \times 80$ & $5(4)$ \\
\hline $72 \times 78$ & $1(1)$ & $72 \times 84$ & $2(2)$ \\
\hline Total & $36(27)$ & & $97(73)$ \\
\hline
\end{tabular}

Table V. Number of screws used for additional fixation

\begin{tabular}{lc}
\hline Number of screws & Frequency (\%) \\
\hline 3 & $15(11)$ \\
4 & $72(54)$ \\
5 & $34(26)$ \\
6 & $11(8)$ \\
7 & $1(1)$ \\
Total & $133(100)$ \\
\hline
\end{tabular}

Table VI. Comparison of pre-operative and final Harris hip score (HHS)

\begin{tabular}{|c|c|c|c|}
\hline & Number valid & Mean (range) & Confidence (SD 95\%) \\
\hline \multicolumn{4}{|l|}{ HHS } \\
\hline Pre-operative & 115 & 53.89 (19 to 84$)$ & $51.41(56.37)$ \\
\hline Final & 115 & 90.38 (67 to 99 ) & 89.41 (91.35) \\
\hline Difference & 115 & 36.49 (7 to 74$)$ & $33.84(39.13)$ \\
\hline
\end{tabular}

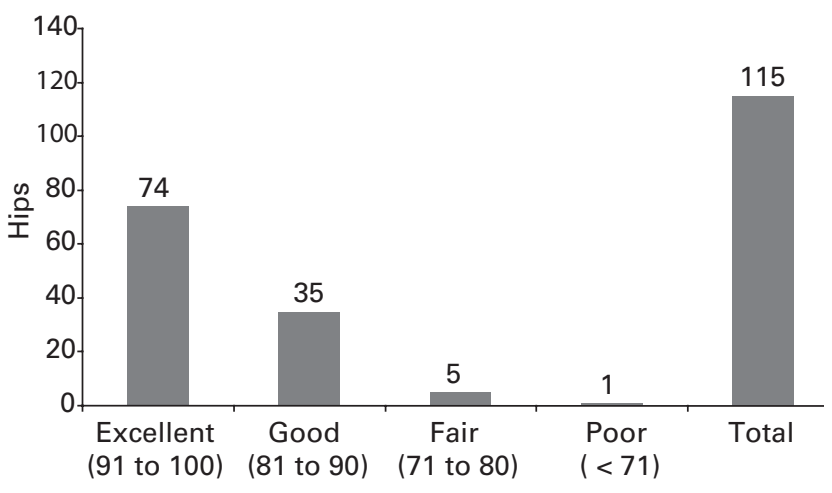

Fig. 1

Bar chart showing the result of 115 hips classified according to the Harris hip score.

the oblong shape as described by Koster et al. ${ }^{16}$ Complete clinical and radiological assessment was obtained for 115 hips. The mean follow-up was for 10.63 years (5 to 14). None of these patients had any clinical evidence of implant failure. The probability of survival was estimated using the Kaplan-Meier method, with further revision or removal of the component taken as the endpoint. The probability of aseptic loosening, excluding deep infection, as the endpoint was also calculated.

Statistics. The statistical software Statistica 8 (StatSoft, Inc., Tulsa, Oklahoma) was used. Differences in survival curves were evaluated by Gehan's Wilcoxon test. ${ }^{24}$ Differences in the variables under study were assessed with the two-tailed Student's $t$-test. A p-value $<0.05$ was considered significant.

\section{Results}

There was a statistically significant improvement in the final HHS compared with before operation $(\mathrm{p}=0.001)$ (Table VI). Most patients were satisfied with the outcome of the surgery (Fig. 1). Many with a fair or poor outcome had problems with the contralateral hip, particularly in patients with rheumatoid arthritis. Radiological data were evaluated from comparison between the post-operative and final radiographs (Table VII). Morcellised allografts were used in all cases with migration of more than $2 \mathrm{~mm}$. Three hips had recurrent dislocation, due to loosening of the 
Table VII. Assessment of radiological data at review

\begin{tabular}{|c|c|c|c|c|c|c|c|c|}
\hline Migration (mm) & Number & Translucency (mm) & $\mathbf{I}$ & Ila & Illb & III & Evaluation of the screws & Number \\
\hline None & 103 & None & 114 & 112 & 97 & 82 & Translucency & 3 \\
\hline$<2$ & 6 & $<1$ sharp & 0 & 1 & 11 & 23 & Fracture & 1 \\
\hline 2 to 5 & 4 & $<2$ sharp & 0 & 1 & 5 & 8 & & \\
\hline$>5$ & 1 & $>2$ sharp & 0 & 0 & 1 & 1 & & \\
\hline
\end{tabular}

Table VIII. Life tables for the series

\begin{tabular}{|c|c|c|c|c|c|c|c|}
\hline \multirow[b]{2}{*}{ Interval start (yrs) } & \multirow[b]{2}{*}{ Number entering } & \multirow[b]{2}{*}{ Number withdrawn } & \multirow[b]{2}{*}{ Number exposed } & \multirow[b]{2}{*}{ Number dying } & \multirow[b]{2}{*}{$\begin{array}{l}\text { Cumulative } \\
\text { proportion surviving }\end{array}$} & \multicolumn{2}{|l|}{$95 \% \mathrm{Cl}^{*}$} \\
\hline & & & & & & Lower bound & $\begin{array}{l}\text { Upper } \\
\text { bound }\end{array}$ \\
\hline \multicolumn{8}{|c|}{ Endpoint: every revision with implant replantation or extraction } \\
\hline 0 & 133 & 0 & 133 & 3 & 1 & 1 & 1 \\
\hline 2 & 130 & 0 & 130 & 8 & 0.98 & 0.95 & 1 \\
\hline 4 & 122 & 2 & 121 & 3 & 0.92 & 0.87 & 0.96 \\
\hline 8 & 110 & 34 & 93 & 1 & 0.87 & 0.82 & 0.92 \\
\hline 10 & 75 & 44 & 53 & 0 & 0.86 & 0.81 & 0.91 \\
\hline 12 & 31 & 31 & 16 & 0 & 0.85 & 0.80 & 0.91 \\
\hline \multicolumn{8}{|c|}{ Endpoint: revision with implant replantation or extraction for aseptic loosening } \\
\hline 0 & 133 & 0 & 133 & 3 & 1 & 1 & 1 \\
\hline 2 & 130 & 5 & 128 & 3 & 0.98 & 0.95 & 1 \\
\hline 6 & 117 & 4 & 115 & 3 & 0.95 & 0.91 & 0.98 \\
\hline 8 & 110 & 34 & 93 & 1 & 0.92 & 0.88 & 0.96 \\
\hline 10 & 75 & 44 & 53 & 0 & 0.91 & 0.87 & 0.96 \\
\hline 12 & 31 & 31 & 16 & 0 & 0.90 & 0.85 & 0.95 \\
\hline
\end{tabular}

* $95 \% \mathrm{Cl}, 95 \%$ confidence interval

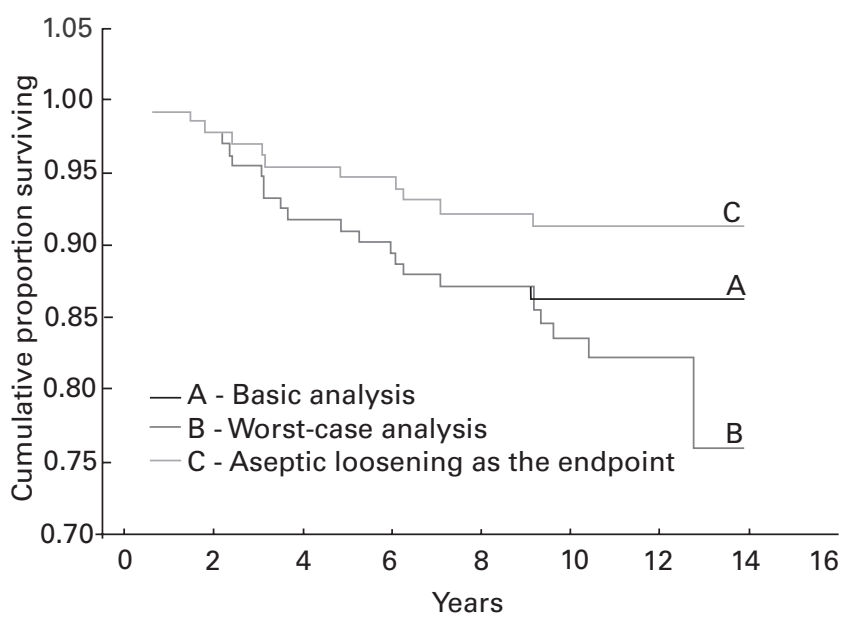

Fig. 2

Kaplan-Meier survival curve showing survival of implant.

acetabular component in two. These components were replaced. The other hip ceased to dislocate after three months in a brace and a change in the rehabilitation regime. Seven cases of deep-vein thrombosis were encountered in the first six weeks after operation and were treated without further complications.

A total of 18 long oblique revision components (13.5\%) were replaced or removed. Aseptic loosening was the reason in 11 cases $(8.3 \%)$ and deep infection in seven $(5.3 \%)$. All septic loosenings occurred following a two-stage procedure after previous deep infection. The probability of survival of the component at 12 years was $0.85 \%$ (95\% confidence interval (CI) 0.80 to 0.91 ), and $0.90 \%$ (95\% CI 0.85 to 0.95 ) when deep infection was excluded as the endpoint (Table VIII). The decrease in the Kaplan-Meier curve in the first three years was clear, and this was also observed in the 'worst-case' analysis, where occurrence of at least one of the three observations of migration of the implant of $>2 \mathrm{~mm}$, translucency in any DeLee area $>2 \mathrm{~mm}$, and fracture of a screw was taken as the endpoint (Fig. 2).

\section{Discussion}

The management of large acetabular defects in revision THR remains challenging. Few publications have described the use of oblong acetabular components. Koster et $\mathrm{al}^{16}$ had a high survival rate of $98.1 \%$ with 109 long oblique revision components, significantly better than the $85 \%$ in our group. Other papers describe variable results. $1,2,6,13,16,17,25,26$ Gotze et $\mathrm{al}^{17}$ found $12 \%$ of aseptic loosening in long 


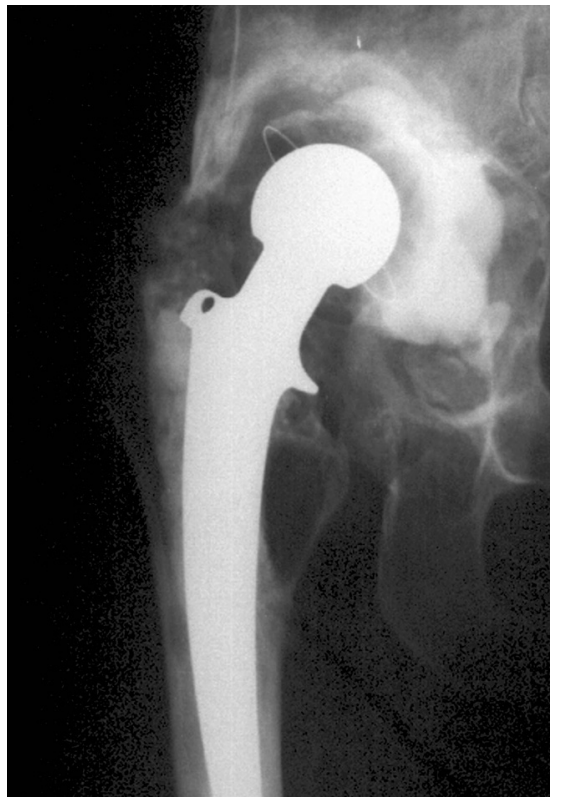

Fig. 3a

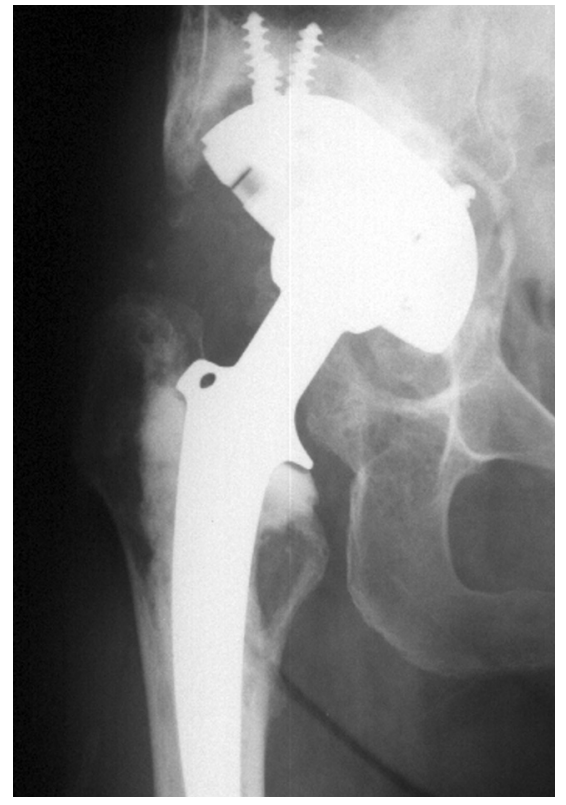

Fig. $3 b$

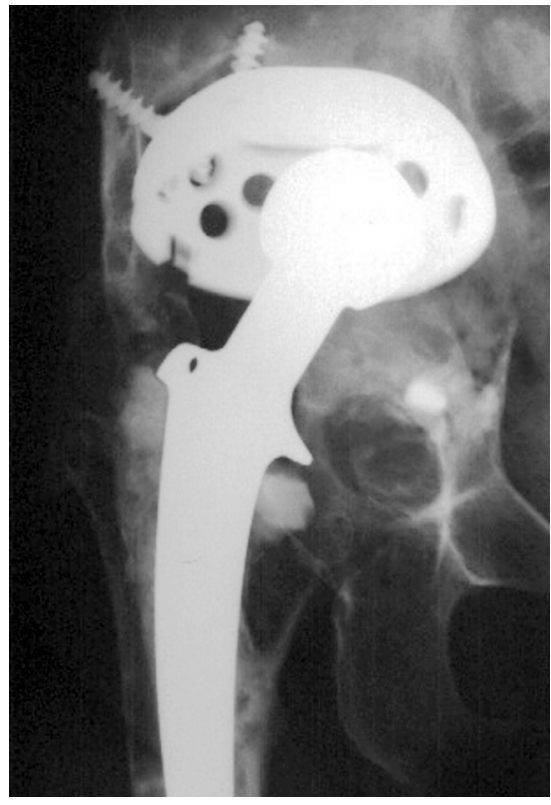

Fig. 3c

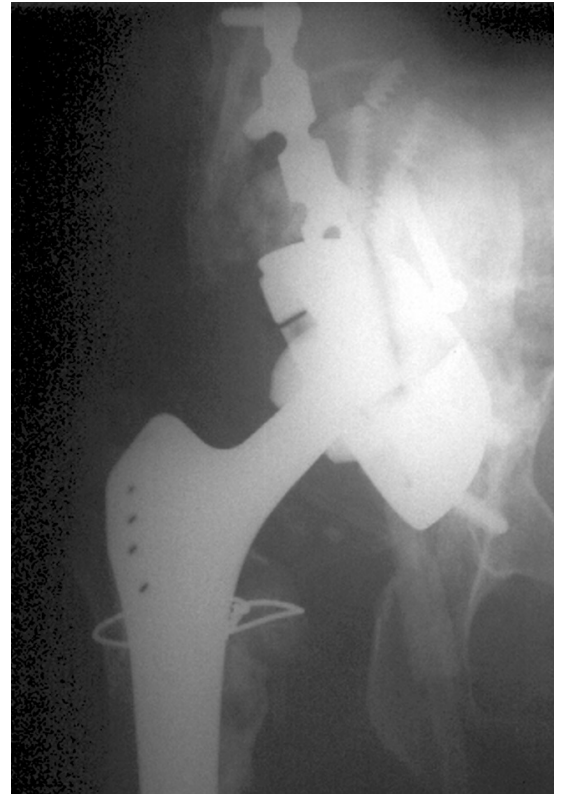

Fig. 3d

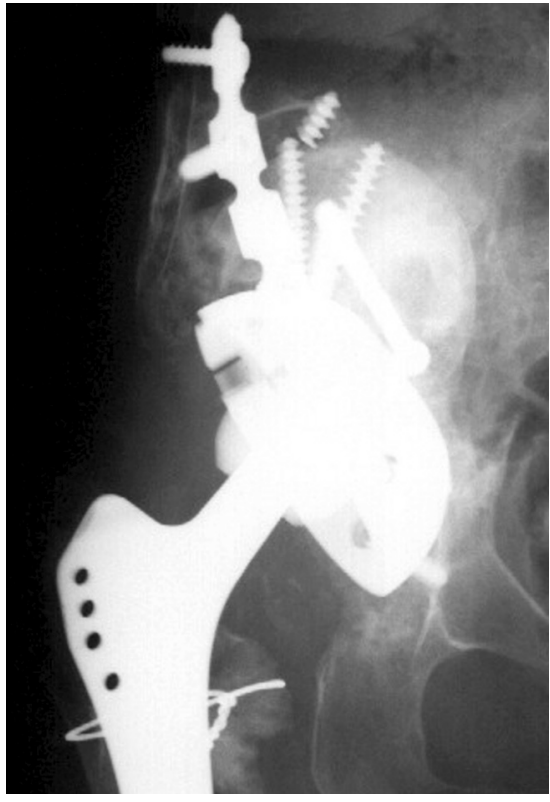

Fig. 3e

Radiographs showing types of loosening of the long oblique revision component: a) Preoperative radiograph, b) relatively small long oblique revision component in a medial position without grafting and without the possibility of anchoring in the distal acetabular vault, c) medial migration two years after the procedure with a defect of the medial and anterior wall, d) Reconstruction of the acetabulum with allograft fixed by a plate from the inner part of pelvis, and a long oblique revision component in the correct position firmly fixed in proximal and distal acetabular vault by screws, e) the same patient and five years after the procedure.

oblique revision components at a mean follow-up of 2.7 years, with lack of contact with the host bone as the main cause. The progressive descent of the Kaplan-Meier curve in our group during the first four years can be attributed to the learning curve and to mistakes in operative technique, usually because of using too small a shell, inadequate bone graft, or failure to ensure distal anchoring with screws. Medial migration and loosening of the component were then seen and observed in four of our cases (Fig. 3). A similar experience was recorded by Chen et al. ${ }^{27}$ However, the large amount of graft required to keep the implant from direct contact with the natural bone bed in the proximal and 


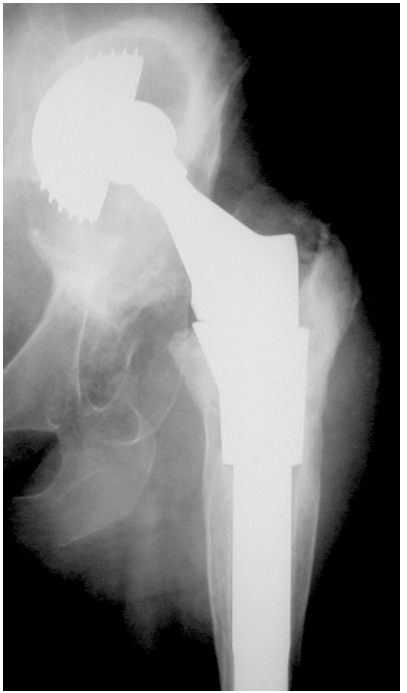

Fig. $4 a$

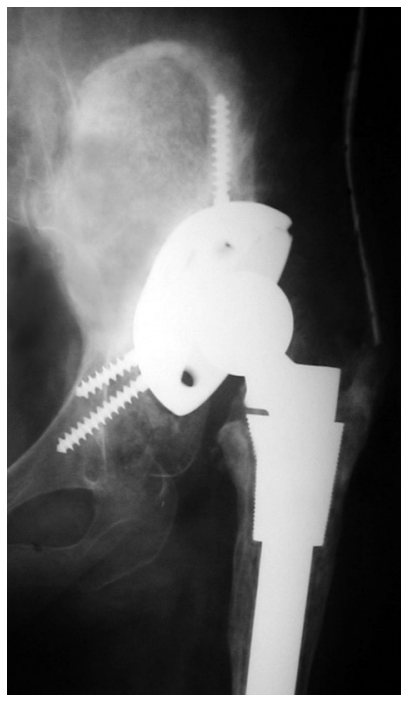

Fig. $4 b$

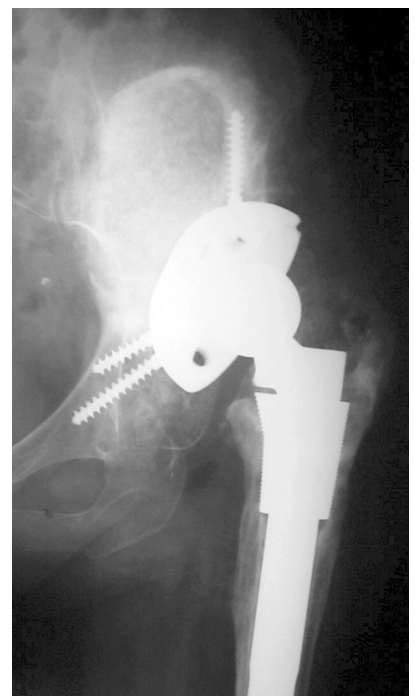

Fig. 4c

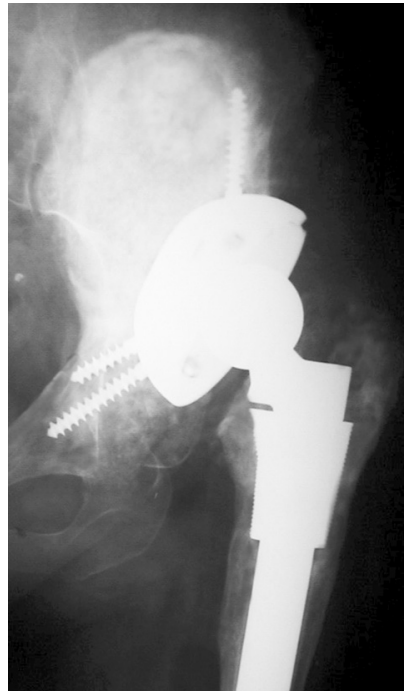

Fig. $4 d$

a) Migration of an uncemented spherical acetabular component to the inner part of pelvis, b) Long oblique revision component anchored into proximal and distal acetabular vault, defect filled by huge amount of morsellised allografts (postoperative radiograph), c) Three years and, d) six years after the procedure.

distal acetabular vault may put at risk the primary stability and osteointegration of the implant, as was seen in three of our cases. However, when the implant was firmly anchored in the proximal and distal parts of the acetabular vault, the relatively thick layer of morcellised allograft integrated without problems (Fig. 4). The remaining four loose components in our series were in type IIIB defects, in which sufficient primary stability was not achieved, relying on a large amount of morcellised allograft.

Good results have been published using jumbo acetabular components, ${ }^{1,2}$ but the indications for this method are limited to type I and II defects. ${ }^{4}$ We prefer to use a standard cementless acetabular component for type I revisions and a long oblique revision component with $6 \mathrm{~mm}$ of ovality for type II. Promising results have been achieved in the short term using $\mathrm{Ti}$ bilobed oblong acetabular components (SROM, DePuy Orthopaedics Inc., Warsaw, Indiana). ${ }^{28,29}$ Impacted morcellised allografts provide an effective and widely accepted method to restore bone stock, and have shown good clinical and radiological results. ${ }^{14,30-32} \mathrm{How}^{-}$ ever, some problems have been reported. Van Haaren et $\mathrm{al}^{33}$ concluded that impaction grafting carries a high risk of complications when used in large segmental defects. We feel that the primary stability of the implant is the essential prerequisite for success and, in the case of large segmental defects this is not attainable by impaction grafting alone. Impacted morcellised allograft must be protected by a support ring firmly fixed to the ilium and ischial tuberosity, ${ }^{34}$ or combined with an oblong acetabular component well anchored in the proximal and distal acetabular vault. The results achieved with the Burch-Schneider device are comparable to ours in large segmental defects. ${ }^{13,25}$ However, we prefer to use the oblong acetabular component, which has the same ability to restore the centre of rotation and normal hip mechanics. Kawanabe et $\mathrm{al}^{35}$ achieved a survival rate of only $53 \%$ at a ten-year follow-up using a combination of morcellised grafts and cemented acetabular component supported by Kerboull reinforcement. An advantage of the oblong acetabular component is that it allows stabilisation of the dorsal column of the acetabulum by a plate in the case of pelvic discontinuity.

Deep infection occurred in $5.2 \%$ of our patients, all of whom had a long oblique revision component implanted six weeks after removal of a component from an infected hip. We consider that placement of morcellised allografts in areas with compromised blood supply limits the local antibiotic levels despite systemic antibiotic therapy. None of these patients had evidence of infection at the time of reimplantation of the prosthesis. The use of vancomycinsupplemented allografts ${ }^{36,37}$ appears to be promising. These can act as a vehicle for vancomycin and allow a high local concentration of antibiotic, ${ }^{38}$ but the determination of the optimal doses is important, as high levels of vancomycin can cause the death of osteoblasts. ${ }^{39}$

Rifampicin-impregnated bone can release antibiotic at an active concentration for at least three weeks after implantation, even after freezing for six months. Biopsy of vancomycin-impregnated bone grafts used to revise hip replacements has shown normal bone formation around the graft, suggesting that vancomycin does not influence bone healing. ${ }^{40,41}$

We believe that the long oblique revision component is the optimal solution for large acetabular defects in revision of THRs. The success of this method depends on correct positioning of the implant, with special attention to stable anchoring by screws in the proximal and distal acetabular 
vault, together with direct press-fit contact of the implant and the natural bone bed. Morcellised bone allografts may be used only as space fillers. The use of the long oblique revision component in the presence of extensive superior and medial acetabular bone defects (type IIIB), when more than two-thirds of the implant has no direct contact with the healthy natural bone bed, is questionable. For this type of defect we prefer to use a large bulk allograft fixed with a plate from the inner part of the pelvis, with an implant that has extensive peri-acetabular anchoring.

This paper was supported by grant MZO 00064203-6604 from the Czech Ministry of Health.

No benefits in any form have been received or will be received from a commercial party related directly or indirectly to the subject of this article.

\section{References}

1. Whaley AL, Berry DJ, Harmsen WS. Extra-large uncemented hemispherical acetabular components for revision total hip arthroplasty. J Bone Joint Surg [Am] 2001;83-A:1352-7

2. Gustke KA. Treatment of large acetabular defects with jumbo cups. Orthopedics 2003;26:379.

3. Çech O, Dzupa V, Svatoš F. The uncemented cup of the CLS Spotorno joint endoprosthesis: 5 years' results. Acta Chir Orthop Traumatol Cech 2001;68:10-17 (in Czech).

4. Cameron HU. Cavity-filling components: when round isn't right. Orthopedics 2001;24:879-80

5. Bozic KJ, Freiburg AA, Harris WH. The high hip center. Clin Orthop 2004;420:101-5.

6. Russotti GM, Harris WH. Proximal placement of the acetabular component in total hip arthroplasty: a long-term follow-up study. J Bone Joint Surg [Am] 1991;73-A:587-92.

7. Kelley S. High hip center in revision arthroplasty. J Arthroplasty 1994;9:503-10.

8. Yoder SA, Brand RA, Pedersen DR, et al. Total hip acetabular component position affects component loosening rates. Clin Orthop 1988;228:79-87.

9. Pagnano MW, Hanssen AD, Lewallen DG, Shaughnessy WJ. The effect of superior placement of the acetabular component on the rate of loosening after total hip arthroplasty. J Bone Joint Surg [Am] 1996;78-A:1004-14

10. Jasty M, Harris WH. Salvage total hip reconstruction in patients with major acetabular bone deficiency using structural femoral head allografts. J Bone Joint Surg [Br] 1990;72-B:63-7.

11. Hooten JP Jr, Engh CA Jr, Engh CA. Failure of structural acetabular allografts in cementless revision hip arthroplasty. J Bone Joint Surg [Br] 1994;76-B:419-22.

12. Gill TJ, Sledge JB, Muller ME. The Burch-Schneider anti-protrusio cage in revision total hip arthroplasty: indications, principles and long-term results. J Bone Joint Surg [Br] 1998;80-B:946-53.

13. Gallo J, Rozkydal Z, Sklenský M. Reconstruction of severe acetabular bone defects using Burch-Schneider cage. Acta Chir Orthop Traumatol Cech 2006;73:15763 (in Czech).

14. Koudela K, Malotin T. Reconstruction of the acetabulum replacement of the aseptically loosened polyethylene cup. Acta Chir Orthop Traumatol Cech 2001;68:162-7 (in Czech).

15. Carroll FA, Hoad-Reddick DA, Kerry RM, Stockley I. The survival of support rings in complex acetabular revision surgery. J Bone Joint Surg [Br] 2008;90-B:574-8.

16. Koster G, Willert HG, Kohler HP, Dopkens K. An oblong revision cup for large acetabular defects: design rationale and two-to seven-year follow-up. J Arthroplasty 1998;13:559-69.

17. Gotze C, Sippel C, Wendt G, Steinbeck J. Limits in cementless hip revision total hip arthroplasty: midterm experience with an oblong revision cup. Z Orthop Ihre Grenzgeb 2003;141:182-9 (in German).
18. Paprosky WG, Momberger NG. Preoperative recognition of acetabular defects: paths of reason. Orthopedics 2000;23:959-60.

19. Bauer R, Kerschbaumer F, Poisel S, Oberthaler W. The transgluteal approach to the hip joint. Arch Orthop Trauma Surg 1979;95:47-9.

20. Harris WH. Traumatic arthritis of the hip after dislocation and acetabular fractures treatment by mold arthroplasty: an end-result study using a new method of evaluation. J Bone Joint Surg [Am] 1969;51-A:737-55

21. Johnston RC, Fitzgerald RH, Harris WH, et al. Clinical and radiographic evaluation of total hip replacement: a standard system of terminology for reporting results. J Bone Joint Surg [Am] 1990;72-A:161-8.

22. Nunn D, Freeman MA, Hill PF, Evans SJ. The measurement of migration of the acetabular component of hip prostheses. J Bone Joint Surg [Br] 1989;71-B:629-31.

23. DeLee JG, Charnley J. Radiological demarcation of cemented sockets in total hip replacement. Clin Orthop 1976;121:20-32.

24. Gehan EA. A generalized Wilcoxon test for comparing arbitrarily singly-censored samples. Biometrika 1965;52:203-23.

25. Gill T, Sledge J, Muller M. The management of severe acetabular bone loss using structural allograft and acetabular reinforcement devices. J Arthroplasty 2000;15:1-7.

26. Berry DJ, Mueller ME. Revision arthroplasty using an anti-protrusio cage for massive acetabular bone deficiency. J Bone Joint Surg [Br] 1992;74-B:711-15.

27. Chen WM, Engh CA Jr, Hopper RH, McAuley JP, Engh CA. Acetabular revision with use of a bilobed component inserted without cement inserted in patients who have acetabular bone-stock deficiency. J Bone Joint Surg [Am] 2000;82-A:197-206.

28. DeBoer DK, Christie MJ. Reconstruction of the deficient acetabulum with an oblong prosthesis: three- to seven-year results. J Arthroplasty 1998;13:674-80.

29. Berry DJ, Sutherland CHJ, Trousdale RT, et al. Bilobed oblong porous coated acetabular components in revision total hip arthroplasty. Clin Orthop 2000;371:154-60.

30. Comba F, Buttaro M, Pusso R, Piccaluga F. Acetabular reconstruction with impacted bone allografts and cemented acetabular components: a 2- to 13-year follow-up study of 142 aseptic revisions. J Bone Joint Surg [Br] 2006;88-B:865-9.

31. Board TN, Rooney P, Kearney JN, Kay PR. Impaction allografting in revision total hip replacement. J Bone Joint Surg [Br] 2006;88-B:852-7.

32. Wang J, Fong CY, Su YS, Yu HN. Acetabular revision with morsellised allogenic bone graft and a cemented metal-backed component. J Bone Joint Surg [Br]2006;88B:586-91.

33. Van Haaren EH, Heyligers IC, Alexander FGM, Wuisman PIJM. High rate of failure of failure of impaction grafting in large acetabular defects. J Bone Joint Surg [Br] 2007;89-B:296-300.

34. Carroll FA, Hoad-Reddick DA, Kerry RM, Stockley I. The survival of support rings in complex acetabular revision surgery. J Bone Joint Surg [Br] 2003;90-B:574-8.

35. Kawanabe K, Akiyama H, Onishi E, Nakamura T. Revision total hip replacement using the Kerboull acetabular reinforcement device with morsellised or bulk allograft: results at a mean follow-up of 8.7 years. J Bone Joint Surg [Br] 2007;89-B:26-31.

36. Buttaro MA, Pusso R, Piccaluga E. Vancomycin-supplemented impacted bone allografts in infected hip arthroplasty: two-stage revision results. J Bone Joint Surg [Br] 2005;87-B:314-19.

37. Buttaro MA, Morandi A, Garcia Rivello H, Piccaluga F. Histology of vancomycin-supplemented impacted bone allografts in revision total hip arthroplasty. J Bone Joint Surg [Br] 2005;87-B:1684-7.

38. Witso E, Persen L, Loseth K, Benum P, Bergh K. Cancellous bone as an antibiotic carrier. Acta Orthop Scand 2000;71:80-4.

39. Edin ML, Miclau TM, Lester GE, Lindsey RW, Dahners LE. Effect of cefazolin and vancomycin on osteoblasts in vivo. Clin Orthop 1996;333:245-51.

40. Delloye C, Cornu O, Druez V, Barbier O. Bone allografts: what they can offer and what they cannot. J Bone Joint Surg [Br] 2007;89-B:574-9.

41. Buttaro M, Araujo GS, Araujo ES, Comba F, Piccaluga F. Viability of impacted bone allografts under metal mesh at the calcar in revision surgery of the hip. J Bone Joint Surg [Br] 2008;90-B:228-31. 